\title{
Reactions of Fluoroalkenes with an Aluminium(I) Complex
}

\author{
Clare Bakewell, Andrew J. P. White and Mark R. Crimmin*
}

\begin{abstract}
A series of industrially relevant fluoroalkenes react with a monomeric $A l(I)$ complex. These reactions break either strong $s p^{2}$ or $s p^{3} C-F$ bonds and result in the formation of a diverse array of organoaluminium compounds. Mechanistic studies show that two mechanisms are likely in operation: Oxidative addition of the $C-F$ bond to $A l(I)$ occurs with retention of alkene stereochemistry, while stepwise formation and decomposition of a metallocyclopropane intermediate occurs with inversion of alkene stereochemistry. As part of this mechanistic analysis, we have isolated the first aluminium metallocyclopropane complex from oxidative addition of an alkene to $A l(I)$. Remarkably this reaction is reversible and reductive elimination of the alkene occurs at higher temperature reforming $A l(I)$. Furthermore, we show that, in selected cases, the organoaluminium products are susceptible toward $\beta$-fluoride elimination yielding a double $C-F$ activation pathway.
\end{abstract}

In 2015 the European Union made a commitment to contain, reduce, and replace gaseous hydrofluorocarbons (HFCs). ${ }^{1}$ Commonly used as refrigerants and aerosols, HFCs are potent contributors to global warming whose use has expanded 10-15\% per annum in recent years. ${ }^{2}$ Fluoroalkenes, specifically hydrofluoroolefins (HFOs), have been billed as next generation refrigerants and are being marketed as direct replacements for HFCs. ${ }^{3,4}$ While HFOs possess significantly lower global warming potentials than HFCs, ${ }^{5}$ questions have been raised about their long term impact in the environment. HFOs are known to degrade to form trifluoroacetic acid (TFA). ${ }^{6}$ The ecological effects of TFA accumulation are unsubstantiated, but given its long lifetime and high Brønstead acidity, it may become detrimental to the environment if the concentration remains unchecked. ${ }^{7}$ In parallel to these practical applications of fluorocarbons, synthetic chemists have developed increasingly sophisticated methods to install fluorine containing groups into pharmaceuticals or agrochemicals. For example, reagents that effect trifluoro-, difluoro- and fluoromethylation of aromatic and heteroaromatic rings are now well established. ${ }^{8-10}$

Based on the emerging trends, there is a clear advantage to developing new chemical transformations that use fluoroalkenes as fluorinated chemical building blocks. To date however, the majority of reactions of HFOs involve either $\mathrm{C}-\mathrm{C}$ or $\mathrm{C}-\mathrm{H}$ bond formation, limiting the opportunity for further synthetic elaboration. ${ }^{11-17}$ Only recently have methods emerged to convert unreactive $\mathrm{C}-\mathrm{F}$ bonds of HFOs into $\mathrm{C}-\mathrm{B}, \mathrm{C}-\mathrm{Si}$ or $\mathrm{C}-\mathrm{Ge}$ bonds. For example, Hosoya and co-workers presented an elegant defluoroborylation of $(E)$-1,3,3,3-tetrafluoropropene and 2,3,3,3tetrafluoropropene with $\mathrm{B}_{2} \mathrm{pin}_{2}$ (bis(pinacolato)diborane) using

[a] Dr. Clare Bakewell, Dr. Andrew J. P. White, Dr. Mark R. Crimmin Department of Chemistry, Imperial College London, South Kensington, London, SW7 2AZ, UK

E-mail: m.crimmin@imperial.ac.uk

Supporting information for this article is given via a link at the end of the document.

catalytic copper salts in the presence of a base. ${ }^{18,19}$ In related studies, Braun and co-workers have documented the hydroboration, hydrosilylation and hydrogermylation of a series of fluoroalkenes, including HFOs, by Lewis acidic heterogeneous catalysts or homogeneous rhodium catalysts. These hydrofunctionalisation reactions often lead to complex mixtures of products due to competing addition and elimination pathways. ${ }^{20-}$ 22

In this paper, we report a method to convert HFOs in to organoaluminium reagents. While we and others have previously shown that the monomeric $\mathrm{Al}(\mathrm{I})$ reagent 1 reacts with $\mathrm{C}-\mathrm{F}$ bonds of fluoroalkanes and fluoroarenes, ${ }^{23,24}$ here we study industrially relevant fluoroalkenes. The methodology is an example of a growing number of approaches in which a low-valent main group metal mimics the redox behaviour of a transition metal. ${ }^{24-30}$ As part of this analysis we have isolated an unprecedented aluminium metallocyclopropane complex and show that the reaction of an alkene with $\mathbf{1}$ is reversible.<smiles></smiles>

dipp $=2,6$-diisopropylphenyl

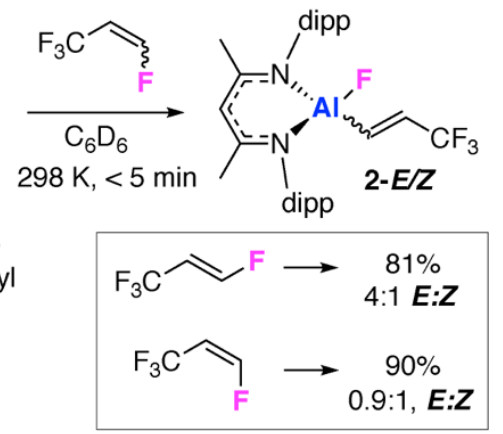

Scheme 1. Reaction of 1 with the stereoisomers of HFO-1234ze

$\mathbf{s} \mathbf{p}^{2} \mathbf{C}-\mathbf{F}$ Bond Activation of Fluoroalkenes: The addition of an excess of $(E)$-1,3,3,3-tetrafluoropropene (HFO-1234ze) to a 18$75 \mathrm{mM}$ solution of $\mathbf{1}$, in $\mathrm{C}_{6} \mathrm{D}_{6}$ at $298 \mathrm{~K}$, resulted in the immediate formation of a $4: 1$ mixture of $\mathbf{2}-\boldsymbol{E}$ and $\mathbf{2}-\boldsymbol{Z}$ (Scheme 1 ). The products could be separated by fractional crystallisation in $n$ hexane and were characterized by multinuclear NMR spectroscopy and X-ray diffraction (Figure 1 ). The product ratio was found to be independent of the initial reaction concentration and repeating the reaction in the presence of a radical inhibitor (9,10-dihydroanthracene) did not affect the selectivity. Monitoring reactions by ${ }^{19} \mathrm{~F}$ and ${ }^{1} \mathrm{H}$ NMR spectroscopy revealed that ratios of 2-E:2-Z do not change as a function of time. Moreover, attempts to equilibrate a pure sample of $2-E$ to a mixture of $2-E$ and $2-Z$ by heat $\left(353 \mathrm{~K}\right.$ in $\left.\mathrm{C}_{6} \mathrm{D}_{6}\right)$ or light (sunlight) were ineffective. These data all suggest that isomerization of the $\mathrm{C}=\mathrm{C}$ bond of the fluoroalkene must occur on the pathway to $\mathrm{C}-\mathrm{F}$ bond activation. In line with this hypothesis, the reaction of 1 with $(Z)-1,3,3,3$ tetrafluoropropene led to the formation of a mixture of $2-E$ and $2-$ $\boldsymbol{Z}$, in a 0.9:1 ratio (Scheme 1). Hence the reaction occurs with partial erosion of the original stereochemistry of the alkene. 


$$
\text { isopropylphenyl }
$$

Scheme 2. Reaction of 1 with HFO-123yf and hexafluoropropene

The scope of $\mathrm{C}-\mathrm{F}$ bond activation was expanded. Addition of 2,3,3,3-tetrafluoropropene (HFO-1234yf) to 1 led to exclusive activation of the $\mathrm{sp}^{2} \mathrm{C}-\mathrm{F}$ bond to form 3 (Scheme 2, Figure 1). The reaction of $\mathbf{1}$ with hexafluoropropene proved more complex with ${ }^{1} \mathrm{H}$ and ${ }^{19} \mathrm{~F}$ NMR spectroscopy revealing the formation of two new compounds $\mathbf{4 a}$ and $\mathbf{4 b}$ in a 1:1.7 ratio (Scheme 2). ${ }^{31} \mathbf{4 a}$ is the result of breaking the internal $\mathrm{sp}^{2} \mathrm{C}-\mathrm{F}$ bond, while $\mathbf{4 b}$ is formed from reaction of the terminal $\mathrm{sp}^{2} \mathrm{C}-\mathrm{F}$ bond, trans to the $\mathrm{CF}_{3}$ group. Again, the products could be separated by fractional crystallisation from $n$-hexane (Figure 1 ). In both cases the $\mathrm{C}=\mathrm{C}$ bond of hexafluoropropene is retained in the organoaluminium compound, with comparable bond lengths of 1.310(6) and $1.325(4) \AA$ in $\mathbf{4 a}$ and $\mathbf{4 b}$ respectively. While the reactivity of hexafluoropropene with $\mathbf{1}$ is consistent with many examples of addition of nucleophiles to this substrate, ${ }^{14,32-36}$ the precise origin of this selectivity remains somewhat unclear.

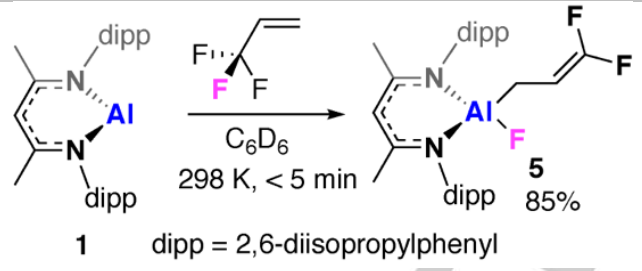

Scheme 3. Reaction of $\mathbf{1}$ with trifluoropropene

$\mathbf{s p}^{3} \mathbf{C}-\mathbf{F}$ Bond Activation of Trifluoropropene: Expanding the investigation to fluoroalkenes that do not contain $\mathrm{sp}^{2} \mathrm{C}-\mathrm{F}$ bonds leads to equally facile $\mathrm{sp}^{3} \mathrm{C}-\mathrm{F}$ bond activation. The reaction of 1 with 3,3,3-trifluoropropene yields 5 (Scheme 3). The ${ }^{19} \mathrm{~F}$ NMR spectrum of $\mathbf{5}$ displays distinctive doublet resonances of the germinal difluoroalkene moiety at $\delta=-94.8\left(\mathrm{~d},{ }^{2} J_{\mathrm{F}-\mathrm{F}}=61.7 \mathrm{~Hz}\right)$ and $-98.0\left(\mathrm{~d},{ }^{2} \mathrm{~J}_{\mathrm{F}-\mathrm{F}}=61.7 \mathrm{~Hz}\right)$ along with the broad singlet resonance of the Al-F moiety at $\delta=-168.3 \mathrm{ppm}$. The ${ }^{1} \mathrm{H}$ NMR spectrum of 5 has a distinctive multiplet at $\delta=0.54 \mathrm{ppm}$, indicative of a methylene group in close proximity to a Lewis acidic metal. $\mathrm{C}-\mathrm{F}$ bond activation has occurred with transposition of the $\mathrm{C}=\mathrm{C}$ bond. The structure of $\mathbf{5}$ was elucidated by single crystal X-ray diffraction (Figure 1), the presence of the $\mathrm{sp}^{2} \mathrm{CF}_{2}$ group is evidenced by a short carbon-carbon bond length (C32-C33, 1.284(4) $\AA$ ) and geometries around the terminal carbon of the fluorinated chain. The formation of a related organometallic species from trifluoropropene has previously been reported upon reaction with $\left[\mathrm{Cp}^{*} \operatorname{Ir}\left(\mathrm{PMe}_{3}\right) \mathrm{H}\right] \mathrm{Li}$ and $\left[\left(\mathrm{PEt}_{3}\right)_{3} \mathrm{Rh}\left(\mathrm{GePh}_{3}\right)\right]$, respectively. ${ }^{34,37} \mathrm{~A}$ similar fluorine elimination followed by transposition of the double bond is observed in Lewis acid mediated 3,3-difluoroallylation reactions between 2-bromo-3,3,3trifluoropropene and arenes. ${ }^{38}$

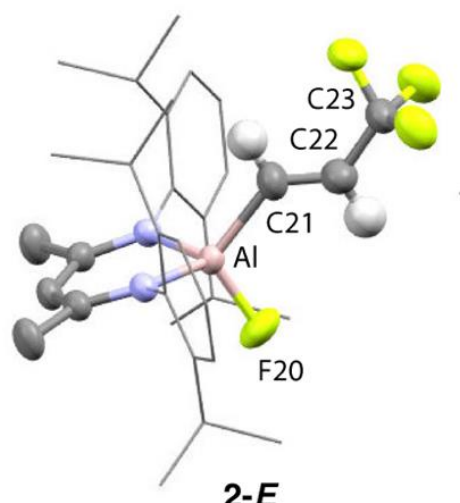

2-E

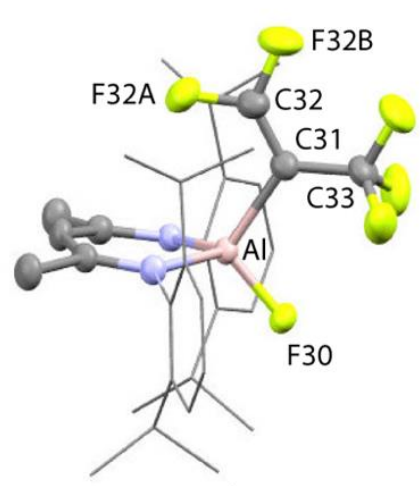

$4 a$

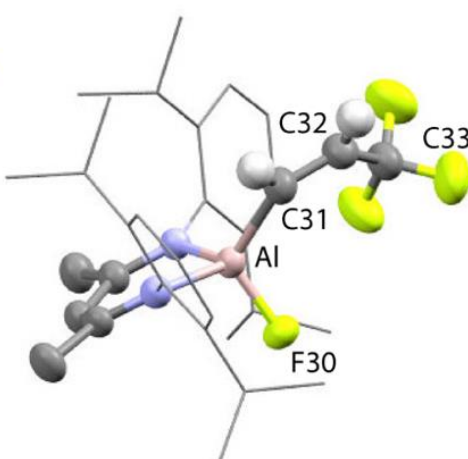

$2-Z$

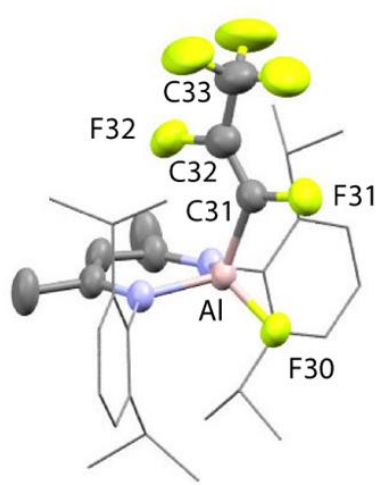

4b

Figure 1. Solid state structures of $2-E, 2-Z, 3,4 a, 4 b$ and 5 .

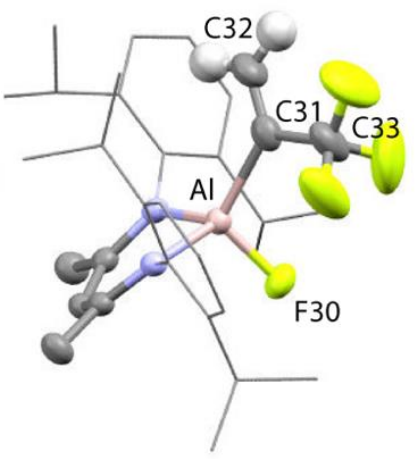

3

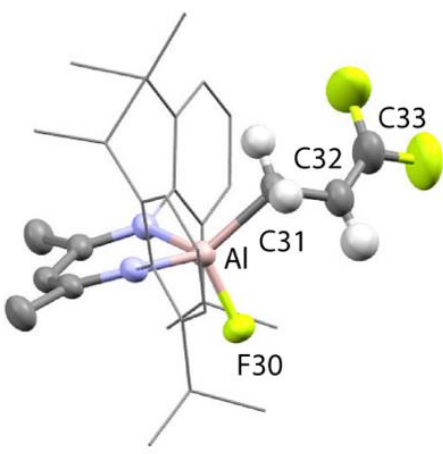

5 
Mechanistic Studies: In combination, the reactions of $\mathbf{1}$ with fluoroalkenes possess a series of interesting mechanistic features that require comment. These include: (i) the partial erosion of alkene E/Z-stereochemistry during $\mathrm{C}-\mathrm{F}$ bond activation, (ii) the facile activation of both $\mathrm{sp}^{3}$ and $\mathrm{sp}^{2} \mathrm{C}-\mathrm{F}$ bonds of fluoroolefins with $\mathbf{1}$, and (iii) the potential for $\mathrm{C}=\mathrm{C}$ bond migration in $\mathrm{C}-\mathrm{F}$ activation. DFT calculations using the $\omega \mathrm{B} 97 \mathrm{x}$ functional and a hybrid SDD/6,31G** basis set were undertaken to investigate the possible $\mathrm{C}-\mathrm{F}$ activation pathways. Our preliminary study focused on both $(E)-1,3,3,3$-tetrafluoropropene and trifluoropropene as in combination they allow the mechanistic points above to be addressed.

Two viable mechanisms for $\mathrm{C}-\mathrm{F}$ bond activation were identified (Figure 2a). The first involves a direct oxidative addition of the $\mathrm{sp}^{2} \mathrm{C}-\mathrm{F}$ bond to $1\left(\Delta \mathrm{G}^{\ddagger}=23.5 \mathrm{kcal} \mathrm{mol}^{-1}\right)$. This mechanism occurs with retention of the alkene stereochemistry. ${ }^{39,40}$ The alternative pathway involves reaction of $\mathbf{1}$ with the alkene to form a metallocyclopropane intermediate $\left(\Delta G^{\ddagger}=27.1 \mathrm{kcal} \mathrm{mol}^{-1}\right)$ that undergoes subsequent $\alpha$-fluoride elimination. $\alpha$-Fluoride elimination was calculated to occur through a concerted transition state (Figure 2a, Newman projection). The formation and decomposition of the metallocyclopropane destroys and reconstructs the $\mathrm{C}=\mathrm{C}$ bond with inversion of the stereochemistry. Consistent with experiment the difference in the calculated activation energies between the retention and inversion pathways is small $\left(\Delta \Delta \mathrm{G}^{\ddagger}=3.6 \mathrm{kcal} \mathrm{mol}^{-1}\right)$ with the former pathway having the lower barrier. While based on this method alone it would be expected that the retention pathway should dominate, upon exploring a series of functionals (Table S3) it was found that the $\Delta \Delta \mathrm{G}^{\ddagger}$ varies between $0.6-3.8 \mathrm{kcal} \mathrm{mol}^{-1}$. The lower end of this range is consistent with competitive retention and inversion pathways which, in combination, explain the partial stereoerosion observed in experiments of HFO-1234-ze with 1.

The reaction of $\mathbf{1}$ with 3,3,3-trifluoropropene is also calculated to proceed by a metallocyclopropane intermediate (Figure $2 b$ ). In this case $\beta$-fluoride elimination results in the formation of 5 and invoking this intermediate provides an explanation for the transposition of the $\mathrm{C}=\mathrm{C}$ double bond observed in experiment.
Following metallocyclopropane formation, both $\alpha$-fluoride $\left(\Delta \mathrm{G}^{\ddagger}=\right.$ $15.2 \mathrm{kcal} \mathrm{mol}^{-1}$ and $\beta$-fluoride elimination $\left(\Delta \mathrm{G}^{\ddagger}=10.7 \mathrm{kcal} \mathrm{mol}^{-1}\right)$ steps are calculated to occur by low-energy barriers.

Although the calculations support the formation of metallocyclopropane intermediates in $\mathrm{C}-\mathrm{F}$ bond activation with 1 there is limited precedent for such species. While $\mathbf{1}$ is known to react with alkynes, ${ }^{26,41}$ reactions with alkenes have not been reported. Attempts to identify a metallocyclopropane intermediate during $\mathrm{C}-\mathrm{F}$ bond activation were unsuccessful. The reaction between 1 and trifluoropropene is fast even at $193 \mathrm{~K}$ leading only to the formation of $\mathbf{5}$. To add weight to the mechanistic hypothesis, the reaction of 1 with a non-fluorinated alkene was investigated. Norbornene reacts with $\mathbf{1}$ to form the metallocyclopropane $\mathbf{6}$ over $5 \mathrm{~h}$ at $298 \mathrm{~K}$ in $\mathrm{C}_{6} \mathrm{D}_{6}$ solution (Figure $2 \mathrm{c}$ ). The relief of ring-strain undoubtedly provides a thermodynamic driving force for this reaction and 6 could be isolated and fully characterized. The single crystal $X$-ray structure shows that $\mathbf{6}$ contains a metallocyclopropane unit with a long $\mathrm{C}-\mathrm{C}$ bond of $1.623(6) \AA$. The Al-N bond distances of $1.8924(13) \AA$ in 6 are $0.07 \AA$ shorter than those found in 1, while the $\mathrm{N}-\mathrm{Al}-\mathrm{N}$ angle of 96.30 (8) is $\sim 6^{\circ}$ is more obtuse. ${ }^{25}$ The solid-state data are consistent with metallocyclopropane formation being defined as an oxidative addition reaction. The bond lengths and angles around aluminium reflect a change from the +1 to +3 oxidation state and the higher charge density at the metal, an assignment that is supported by DFT calculations which show that the charge on Al in 6 is far more electropositive than in $\mathbf{1}$ (supporting information, Table S5).

The addition of norbornene to $\mathbf{1}$ is reversible and at high temperatures $(>333 \mathrm{~K})$ the alkene is released and $\mathbf{1}$ is regenerated, as demonstrated in the variable temperature ${ }^{1} \mathrm{H}$ NMR spectrum (Figure S1). While reversible alkene coordination to transition metals is a fundamental step often invoked in catalysis, examples of reversible reaction with main group reagents are exceptionally rare. ${ }^{42,43}$ Due to the reductive elimination of norbornene from 6 being accessible, at high temperatures 6 can act as a 'masked' $\mathrm{Al}(\mathrm{I})$ reagent and will react with 3,3,3-trifluoropropene to yield $\mathbf{5} .^{24}$
(1)

)

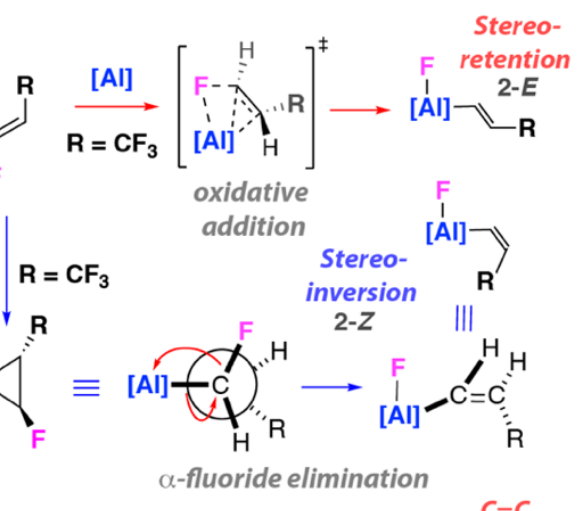

(b)

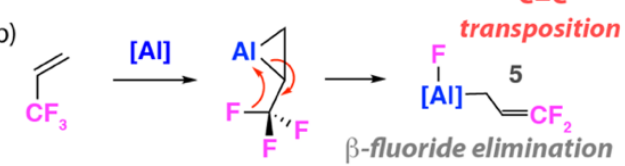

(c)<smiles>CC1=CC(C)=[N+]([AlH])[AlH]N1[GeH3]</smiles>

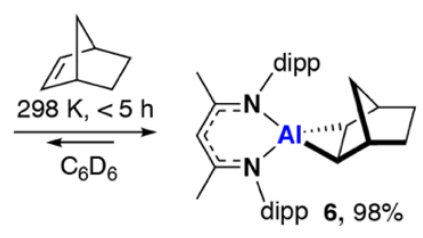

(d)

1
[AI]

isolable

metallocyclopropane

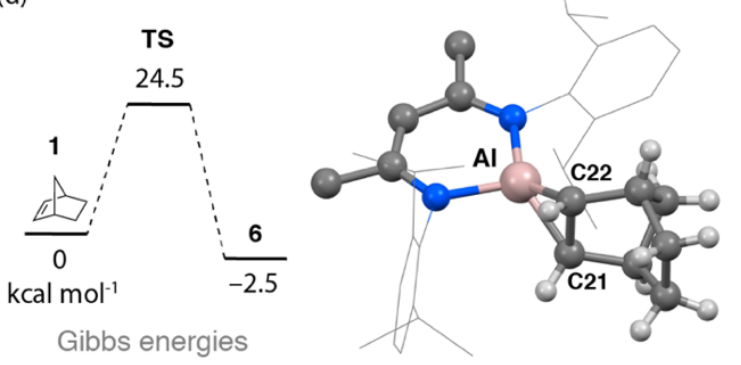

Figure 2. (a) Proposed mechanism for the reaction of HFO-1234ze with 1, (b) proposed mechanism for the reaction of trifluoropropene with 1, (c) preparation and reactivity of a metallocyclopropane complex 6 , (d) calculated reaction pathway for the reaction of 1 with norbornene and solid-state structure of 6 . 
Thermal Stability and Double C-F Bond Activation: Transition metal and s-block complexes bearing partially fluorinated groups are well known to decompose by $\beta$-fluoride elimination. ${ }^{17,44-47}$ But while $\beta$-hydride elimination occurs in tri-iso-butylaluminium at high temperatures, ${ }^{48} \beta$-fluoride elimination is less well studied in organoaluminium chemistry. The thermal stability of 2-5 in benzene solution was probed to gauge the ease of fluoride elimination. While $\mathbf{2}-\boldsymbol{E}, \mathbf{2}-\mathbf{Z}, \mathbf{4} \mathbf{b}$ and $\mathbf{5}$ were found to be stable at high temperatures for prolonged periods of time $(353 \mathrm{~K} ;>1$ week), both 3 and $\mathbf{4 a}$ fragmented when heated to $353 \mathrm{~K}$. The organic fragments were identified as 1,1-difluoroallene (from 3 ) and tetrafluoroallene (from $4 \mathbf{a}$ ); both form alongside the expected aluminium difluoride $\mathbf{1}-\mathbf{F}_{\mathbf{2}}$ which has also been isolated and fully characterized (Scheme 4). ${ }^{49-51}$

(a)

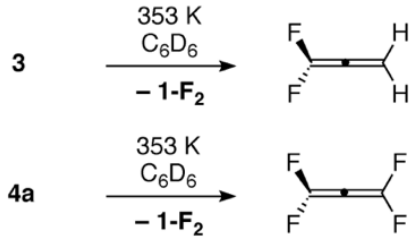

(b) dipp

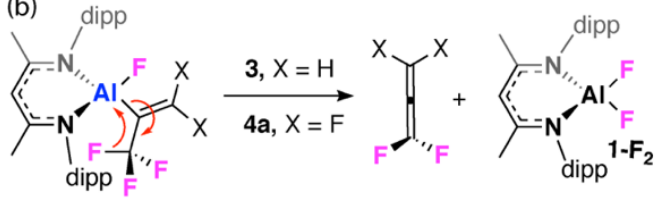

(c)

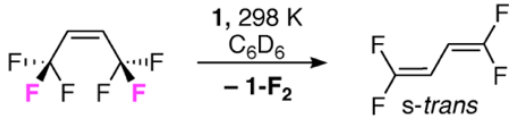

Scheme 4. (a) Thermal Stability of $\mathbf{3}$ and $\mathbf{4 a}$, (b) Proposed mechanism of $\beta$ fluoride elimination, and (c) double C-F activation of 1,1,1,3,3,3hexafluorobutene

The net pathway from $\mathbf{1}$ is a double $\mathrm{C}-\mathrm{F}$ activation of fluoroalkenes leading to new fluorinated allenes. In the case of 3 and $4 \mathrm{a}$ the second $\mathrm{C}-\mathrm{F}$ bond cleavage step is extremely slow. At $353 \mathrm{~K} 4 \mathbf{a}$ has a half-life of $\sim 6$ days. For comparison the first $\mathrm{C}-\mathrm{F}$ bond cleavage is fast, $\mathbf{4 a}$ forms from $\mathbf{1}$ and hexafluoropropene within minutes at $298 \mathrm{~K}$. A further reaction between 1 and 10 equiv. of 1,1,1,4,4,4-hexafluoro-2-butene (HFO-1336-mzz) did not allow the isolation of a new organoaluminium compound but instead led to the formation of $s$-trans isomer of 1,1,4,4tetrafluorobutadiene and $\mathbf{1}-\mathbf{F}_{2}{ }^{52,53}$ While the unambiguous assignment of this pathway will have to await a full mechanistic study, it appears in this case the rate of the second $\mathrm{C}-\mathrm{F}$ bond cleavage step is either similar to or faster than the first, possibly due to the ease of 1,3-diene formation over allene formation, leading directly to the organic product.

In summary, we report the preparation of an array of fluorinated organoaluminium compounds from reaction of fluoroalkenes with an aluminium(I) complex. DFT calculations and initial mechanistic experiments are consistent with $\mathrm{C}-\mathrm{F}$ activation occurring by either a direct oxidative addition step or formation of a metallocyclopropane intermediate followed by either $\alpha$ - or $\beta$ fluoride elimination. The new fluorinated organoaluminium compounds each contain fragments with 3-carbon atoms but have diverse fluorine content along with different connectivity and
3D-shapes. We are currently investigating these compounds as nucleophilic sources of $\left\{\mathrm{C}_{3} \mathrm{~F}_{5}\right\}^{-},\left\{\mathrm{C}_{3} \mathrm{~F}_{3} \mathrm{H}_{2}\right\}^{-}$and $\left\{\mathrm{C}_{3} \mathrm{~F}_{2} \mathrm{H}_{3}\right\}^{-}$in synthesis.

\section{Acknowledgements}

We are grateful to the Royal Society for provision of a University Research Fellowship (MRC) and to the Leverhulme Trust (RPG2015-248) and ERC (FluoroFix: 677367) for generous funding. Bryan J. Ward is thanked for assistance with DFT calculations.

Keywords: Carbon-Fluorine Bond Activation - HFOs • Aluminium • Fluoride Elimination • Fluoroolefins

(1) https://ec.europa.eu/clima/policies/f-gas/legislation_da (accessed: April 2018)

(2) Velders, G. J. M.; Ravishankara, A. R.; Miller, M. K.; Molina, M. J.; Alcamo, J.; Daniel, J. S.; Fahey, D. W.; Montzka, S. A. Reimann, S. Science 2012, 335 (6071), 922.

https://www.honeywell.com/newsroom/pressreleases/2014/0 9/honeywell-to-increase-production-of-low-global-warmingmaterials-reduce-hydrofluorocarbon-hfc-production-bynearly-half-over-five-years (accessed: April 2018).

https://www.honeywell.com/newsroom/pressreleases/2015/0 $1 /$ honeywell-starts-full-scale-production-of-low-globalwarming-propellant-insulating-agent-and-refrigerant (accessed: April 2018).

(5) http://www.ipcc.ch/publications_and_data/ar4/wg1/en/ch2s2 10-2.html (accessed: April 18).

Franklin, J. Chemosphere 1993, 27 (8), 1565

(7) Solomon, K. R.; Velders, G. J. M.; Wilson, S. R.; Madronich, S.; Longstreth, J.; Aucamp, P. J.; Bornman, J. F. J. Toxicol. Environ. Health B 2016, 19 (7), 289.

(8) Tomashenko, O. A.; Grushin, V. V. Chem. Rev. 2011, 111 (8), 4475.

(9) Yerien, D. E.; Barata-Vallejo, S.; Postigo, A. Chem. Eur. J. 2017, 23 (59), 14676.

(10) Alonso, C.; Martínez de Marigorta, E.; Rubiales, G.; Palacios F. Chem. Rev. 2015, 115 (4), 1847.

Vela, J.; Smith, J. M.; Yu, Y.; Ketterer, N. A.; Flaschenriem C. J.; Lachicotte, R. J.; Holland, P. L. J. Am. Chem. Soc. 2005, 127 (21), 7857

$\begin{array}{ll}\text { (12) } & \text { Douvris, C.; Ozerov, O. V. Science 2008, } 321 \text { (5893), } 1188 . \\ \text { (13) } & \text { Douvris, C.; Nagaraja, C. M.; Chen, C.-H.; Foxman, B. M.; }\end{array}$ Ozerov, O. V. J. Am. Chem. Soc. 2010, $132(13), 4946$

(14) Braun, T.; Noveski, D.; Neumann, B.; Stammler, H.-G.
Angew. Chem. Int. Ed. 2002, 41 (15), 2745.

(14) Braun, T.; Noveski, D.; Neumann, B.; Stammler, H.-G.
Angew. Chem. Int. Ed. 2002, 41 (15), 2745. (15) Kühnel, M. F.; Lentz, D. Angew. Chem. Int. Ed. 2010, 49 (16), 2933.

(16) Clot, E.; Mégret, C.; Kraft, B. M.; Eisenstein, O.; Jones, W. D J. Am. Chem. Soc. 2004, 126 (17), 5647.

(17) Kraft, B. M.; Jones, W. D. J. Am. Chem. Soc. 2002, 124 (29) 8681.

(18) Sakaguchi, H.; Uetake, Y.; Ohashi, M.; Niwa, T.; Ogoshi, S.; Hosoya, T. J. Am. Chem. Soc. 2017, 139 (36), 12855.

(19) Sakaguchi, H.; Ohashi, M.; Ogoshi, S. Angew. Chem. Int. Ed. 2018, 57, 328. Braun, T.; Ahijado Salomon, M.; Altenhöner, K.; Teltewskoi

M.; Hinze, S. Angew. Chem. Int. Ed. 2009, 48 (10), 1818.

Braun, T.; Wehmeier, F.; Altenhöner, K. Angew. Chem. Int. Ed. 2007, 46 (28), 5321.

Meißner, G.; Kretschmar, K.; Braun, T.; Kemnitz, E. Angew. Chem. Int. Ed. 2017, 39, 3241.

(23) Jones, C. Nat. Rev. Chem. 2017, 1, 0059. 2014, 136 (25), 9195.

(25) Cui, C.; Roesky, H. W.; Schmidt, H.-G.; Noltemeyer, M.; Hao, H.; Cimpoesu, F. Angew. Chem. Int. Ed. 2000, 39 (23), 4274. Zhu, H.; Chai, J.; Fan, H.; Roesky, H. W.; He, C.; Jancik, V.; Schmidt, H.-G.; Noltemeyer, M.; Merrill, W. A.; Power, P. P. Angew. Chem. Int. Ed. 2005, 44 (32), 5090. 
(27) Zhu, H.; Chai, J.; Chandrasekhar, V.; Roesky, H. W.; Magull, J.; Vidovic, D.; Schmidt, H.-G.; Noltemeyer, M.; Power, P. P.; Merrill, W. A. J. Am. Chem. Soc. 2004, 126 (31), 9472.

(28) Ganesamoorthy, C.; Bläser, D.; Wölper, C.; Schulz, S. Angew. Chem. Int. Ed. 2014, 53 (43), 11587.

(29) Crimmin, M. R.; Butler, M. J.; White, A. J. P. Chem. Commun. 2015, 51, 15994.

(30) Chu, T.; Boyko, Y.; Korobkov, I.; Nikonov, G. I. Organometallics 2015, 34 (22), 5363.

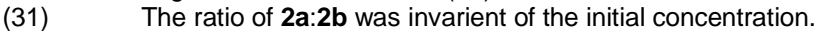

(32) Leclerc, M. C.; Gabidullin, B. M.; Da Gama, J. G.; Daifuku, S. L.; Iannuzzi, T. E.; Neidig, M. L.; Baker, R. T. Organometallics 2017, 36 (4), 849.

(33) Xu, W.; Sun, H.; Xiong, Z.; Li, X. Organometallics 2013, 32 (23), 7122.

(34) Peterson, T. H.; Golden, J. T.; Bergman, R. G. Organometallics 1999, 18 (10), 2005. Ohashi, M.; Shibata, M.; Ogoshi, S. Angew. Chem. Int. Ed. 2014, 53 (49), 13578.

Maples, P. K.; Green, M.; Stone, F. G. A. J. Chem. Soc., Dalton Trans. 1973, 2069

(37) Ahrens, T.; Teltewskoi, M.; Ahrens, M.; Braun, T.; Laubenstein, R. Dalton Trans. 2016, 45, 17495.

(38) Fuchibe, K.; Hatta, H.; Oh, K.; Oki, R.; Ichikawa, J. Angew. Chem. 2017, 129 (21), 5984.

(39) Pitsch, C. E.; Wang, X. Chem. Commun. 2017, 53, 8196.
$38(2), 282$.

Zhu, H.; Oswald, R. B.; Fan, H.; Roesky, H. W.; Ma, Q.; Yang, Z.; Schmidt, H.-G.; Noltemeyer, M.; Starke, K.; Hosmane, N. S. J. Am. Chem. Soc. 2006, 128 (15), 5100.

(42) Boutland, A. J.; Carroll, A.; Alvarez Lamsfus, C.; Stasch, A.; Maron, L.; Jones, C. J. Am. Chem. Soc. 2017, 139 (50), 18190.

(43) Peng, Y.; Ellis, B. D.; Wang, X.; Fettinger, J. C.; Power, P. P Science 2009, 325, 1668

(44) Dixon, S. J. Org. Chem. 1956, 21 (4), 400.

(45) Watson, L. A.; Yandulov, D. V.; Caulton, K. G. J. Am. Chem Soc. 2001, 123 (4), 603

(46) Wada, S.; Jordan, R. F. Angew. Chem. Int. Ed. 2017, 56 (7), 1820.

(47) Gianetti, T. L.; Bergman, R. G.; Arnold, J. J. Am. Chem. Soc. 2013, 135 (22), 8145

(48) $\quad$ Egger, K. W. J. Am. Chem. Soc. 1969, 91 (11), 2867.

(49) Dolbier, W. R.; Burkholder, C. R.; Piedrahita, C. A. J. Fluorine Chem. 1982, 20, 637.

(50) Lu, H.; Friedrich, H. B.; Burton, D. J. J. Fluorine Chem. 1995 75, 83.

(51) Yow, S.; Gates, S. J.; White, A. J. P.; Crimmin, M. R. Angew Chem. Int. Ed. 2012, 51, 12559.

(52) Ehm, C.; Akkerman, F. A.; Lentz, D. J. Fluorine Chem. 2010 $131(11), 1173$.

(53) Bach, A.; Lentz, D.; Luger, P.; Messerschmidt, M.; Olesch, C.; Patzschke, M. Angew. Chem. Int. Ed. 2002, 41, 296. 